\title{
TU/e EmonONEN

\section{Increased speed of analysis in directly coupled gas chromatography-mass spectrometry systems}

\section{Citation for published version (APA):}

Cramers, C. A. M. G., Scherpenzeel, G. J., \& Leclercq, P. A. (1981). Increased speed of analysis in directly coupled gas chromatography-mass spectrometry systems: capillary columns at sub-atmospheric outlet pressures. Journal of Chromatography, 203, 207-216. https://doi.org/10.1016/S0021-9673(00)80294-0

DOI:

10.1016/S0021-9673(00)80294-0

Document status and date:

Published: 01/01/1981

\section{Document Version:}

Publisher's PDF, also known as Version of Record (includes final page, issue and volume numbers)

\section{Please check the document version of this publication:}

- A submitted manuscript is the version of the article upon submission and before peer-review. There can be important differences between the submitted version and the official published version of record. People interested in the research are advised to contact the author for the final version of the publication, or visit the $\mathrm{DOI}$ to the publisher's website.

- The final author version and the galley proof are versions of the publication after peer review.

- The final published version features the final layout of the paper including the volume, issue and page numbers.

Link to publication

\section{General rights}

Copyright and moral rights for the publications made accessible in the public portal are retained by the authors and/or other copyright owners and it is a condition of accessing publications that users recognise and abide by the legal requirements associated with these rights.

- Users may download and print one copy of any publication from the public portal for the purpose of private study or research.

- You may not further distribute the material or use it for any profit-making activity or commercial gain

- You may freely distribute the URL identifying the publication in the public portal.

If the publication is distributed under the terms of Article 25fa of the Dutch Copyright Act, indicated by the "Taverne" license above, please follow below link for the End User Agreement:

www.tue.nl/taverne

Take down policy

If you believe that this document breaches copyright please contact us at:

openaccess@tue.nl

providing details and we will investigate your claim. 
Journal of Chromatography, 203 (1981) 207-216

Elsevier Scientific Publishing Company Amsterdam - Printed in The Netherlands

CHROM. 13,085

INCREASED SPEED OF ANALYSIS IN DIRECTLY COUPLED GAS CHROMATOGRAPHY-MASS SPECTROMETRY SYSTEMS

\title{
CAPILLARY COLUMNS AT SUB-ATMOSPHERIC OUTLET PRESSIJRES
}

\author{
C. A. CRAMERS, G. J. SCHERPENZEEL and P. A. LECLERCQ*
}

Laboratory of Instrumental Analysis, Eindhoven University of Technology, P.O. Box 513, 5600 MB Eindhoven (The Netherlands)

SUMMARY

A theoretical treatment of the optimum gas chromatographic conditions for open-tubular columns, operated at vacuum outlet pressures, is presented. Equations are given for the minimum plate height, the optimum linear gas velocity and the optimum inlet pressure. The maximum column efficiency was calculated to decrease by $12.5 \%$ at most, compared with atmospheric outlet conditions. The gain in speed of analysis obtained with vacuum outlet columns is dependent upon the nature of the carrier gas and increases strongly with lower (sub-atmospheric) optimum inlet pressures. The use of short and/or wide-bore columns can therefore be recommended.

Experimental results indicate the validity of the theory, although no loss in efficiency has been observed. The ultimate gas chromatography-mass spectrometry coupling device thus appears to be no device at all: the end of the column need only be inserted into the ion source of a mass spectrometer. In addition to the gain in speed of analysis, the many problems caused by wall effects and dead volumes in interface lines are avoided by this method. Moreover, the gas chromatographic peaks are narrower and thus higher, lowering detection limits.

\section{INTRODUCTION}

The utility of integrated gas chromatography-mass spectrometry (GC-MS) systems is maximized when (glass) capillary columns are used. Apart from molecular separators as interfaces, there are basically two coupling devices: direct (closed) and open-split connections (see, for instance, refs. 1 and 2 , respectively).

The direct connection has the obvious advantage of full sample transfer. If no restriction is used between the capillary column and the ion source, the column outlet is at a very low pressure. It is often claimed that a decreased outlet pressure has a deleterious effect on column efficiency. In practice ${ }^{3.4}$, up to $30 \%$ loss in optimum separation efficiency has been reported. Other workers reported no loss ${ }^{5.6}$ or even improved resolution ${ }^{7}$ with vacuum outlet pressures. On the other hand, the optimum gas velocity was found to be shifted to higher values ${ }^{3.4}$. 
Although some attempts have been made to rationalize these (contradictory) findings ${ }^{3.4 .16}$, no complete treatment of vacuum-outlet $\mathrm{GC}$ has been reported to date. In this paper it will be shown that operation of wall-coated open-tubular columns at vacuum outlet pressure has many advantages over operation at atmospheric outlet pressures.

\section{EXPERIMENTAL}

A Duran 50 glass capillary $(60 \mathrm{~m} \times 0.40 \mathrm{~mm}$ I.D.) was leached with $\mathrm{HCl}$, dehydrated and subsequently deactivated with benzyltriphenylphosphonium chloride ${ }^{8}$. The column was coated with SE-30 by a static procedure?. The film thickness was calculated to be $0.40 \mu \mathrm{m}$.

The column was operated isothermally at $400^{\circ} \mathrm{K}$. In vacuum outlet GC-MS mode, the column was coupled directly to a Finnigan 4000 quadrupole mass spectrometer (Finnigan, Sunnyvale, CA, U.S.A.), via a glass-lined tube $(40 \mathrm{~cm} \times 0.4 \mathrm{~mm}$ I.D.) (GLT). The GLT was inserted as far as possible into the standard Finnigan 4000 GC-MS interface block. The column was connected to the other end of the GLT by a "graph-pack" coupling ${ }^{10}$. The GLT was maintained at $430^{\circ} \mathrm{K}$. The mass spectrometer was used in the electron impact (EI) mode to monitor the current of alkyl fragment ions at $m / z 15$ (helium carrier gas) or $m / z 43$ (nitrogen), respectively. Chromatograms were recorded on a Leeds \& Northrup Speedomax XL 681 A (Leeds \& Northrup Italiana, Milan, Italy) fast pen recorder.

The column was subsequently divided into two parts each of $30 \mathrm{~m}$ length. One half was used to compare vacuum outlet with atmospheric outlet behaviour. In the latter case a Carlo Erba Fractovap 2900 gas chromatograph (Carlo Erba, Milan, Italy), equipped with a fiame-ionization detector (FID) was employed. Sample splitters, with a splitting ratio of $1: 200$, were used as injector at $550^{\circ} \mathrm{K}$ throughout the experiments. Injections at sub-atmospheric inlet pressures were made by attaching a vacuum pump to the vent outlet of the splitter. The inlet pressure was regulated by a fine metering valve and measured with a Model FA 145 precision pressure gauge (Wallace \& Tierman, Günzburg/Do., G.F.R.).

$n$-Dodecane, having a capacity ratio of $k=2$ at $400^{\circ} \mathrm{K}$, was injected as vapour. The carrier gas velocities were measured using methane (helium carrier gas), or propane (nitrogen), injected simultaneously with $n$-dodecane.

\section{THEORETICAL DISCUSSION}

Band broadening in capillary columns is satisfactorily described by the Golay equation ${ }^{11}$ extended to situations of appreciable pressure drop by Giddings and coworkers ${ }^{12.13}$. Taking into account the decompression effect as described by these authors, the expression for the measured or apparent plate height for a uniformly distributed liquid film, is:

$$
H=\left[2 \frac{D_{\mathrm{m}, \mathrm{o}}}{v_{\mathrm{o}}}+\frac{11 k^{2}+6 k+1}{24(1+k)^{2}} \cdot \frac{r^{2} v_{\mathrm{o}}}{D_{\mathrm{m}, \mathrm{o}}}\right] f_{1}+\frac{k^{3}}{6(1+k)^{2}} \cdot \frac{r^{2}}{k^{2} D_{\mathrm{s}}} v_{\mathrm{o}} f_{2}
$$


This equation describes the effect of pressure gradient on the observed plate height, $H$. Defining $P=P_{\mathrm{i}} / P_{\mathrm{o}}$ as the ratio of inlet to outlet pressure

$$
f_{1}=\frac{9}{8} \frac{\left(P^{4}-1\right)\left(P^{2}-1\right)}{\left(P^{3}-1\right)^{2}} \text { (Giddings correction factor) }
$$

where $f_{1}=1$ for $P=1$, and $f_{1}=9 / 8$ for $P \rightarrow \infty$

$$
f_{2}=\frac{3}{2} \frac{P^{2}-1}{P^{3}-1} \text { (Martin-James correction factor) }
$$

where $f_{2}=1$ for $P=1$, and $f_{2}=3 /(2 P)$ for $P \rightarrow \infty$.

In eqn. 1 the following symbols are used:

$D_{\mathrm{m}, \mathrm{o}}$ is the diffusion coefficient of a component in the mobile phase at column outlet pressure.

$v_{0}$ is the linear velocity at the column outlet, and is related to the retention time, $t_{\mathrm{o}}$, of an unretained component, column length $L, f_{2}$ and the average carrier gas velocity, $\bar{v}$, as:

$$
v_{\mathrm{o}}=\frac{\bar{v}}{f_{2}}=\frac{L}{t_{\mathrm{o}} f_{2}}
$$

$D_{\mathrm{s}}$ is the diffusion coefficient of a component in the stationary liquid phase.

$r$ is the column radius.

$k$ is the capacity ratio of a solute and is equal to $K \cdot \beta$.

$K$ is the partition coefficient of a solute.

$\beta$ is the volume ratio of the stationary and mobile phases, $V_{\mathrm{s}} / V_{\mathrm{m}}$.

Eqn. 1 can be written in a simplified form:

$$
H=\left[\frac{B_{\mathrm{o}}}{v_{\mathrm{o}}}+C_{\mathrm{m} . \mathrm{o}} v_{\mathrm{o}}\right] f_{1}+C_{\mathrm{s}} v_{\mathrm{o}} f_{2}
$$

The effect of operating at sub-atmospheric column outlet pressures is dependent on the relative magnitude of the $C_{\mathrm{m}}$ and $C_{\mathrm{s}}$ terms (describing the resistance to mass transfer in the gas and liquid phases respectively). A treatment including the $C_{\mathrm{s}}$ term will be given in a forthcoming paper.

\section{Assumptions}

In a first approximation it will be assumed that $C_{\mathrm{s}}$ is negligible compared to $C_{\mathrm{m}}$. At the same time $P \gg 1$, if no restriction is used at the outlet of the column directly connected to the ion source of a mass spectrometer. The effect of these assumptions will be treated systematically.

\section{Optimum chromatographic conditions}

By differentiating eqn. 5 or eqn. 1 with respect to $v_{0}$, and setting the result equal to zero, the optimum value of $v_{0}$ and the minimum value of $H$ are found. It has been shown ${ }^{14}$ that, if $C_{\mathrm{m}} \gg C_{\mathrm{s}}$, this differentiation yieids the following equations describing the optimum GC conditions

$$
v_{\mathrm{o}, \mathrm{opt}}=\sqrt{\frac{B_{\mathrm{c}}}{C_{\mathrm{m}, \mathrm{o}}}}=4 \frac{D_{\mathrm{m}, \mathrm{o}}}{r} \sqrt{\frac{3(1+k)^{2}}{11 k^{2}+6 k+1}}
$$


and using eqn. 4 :

$$
\begin{aligned}
& \bar{v}_{\mathrm{opt}}=\frac{4 D_{\mathrm{m}, \mathrm{o}}}{r} f_{2, \mathrm{opt}} \sqrt{\frac{3(1+k)^{2}}{11 k^{2}+6 k+1}} \\
& H_{\mathrm{min}}=2 f_{1, \mathrm{opt}} \sqrt{B_{\mathrm{o}} C_{\mathrm{m}, \mathrm{o}}}=f_{1, \mathrm{opt}} r \sqrt{\frac{11 k^{2}+6 k+1}{3(1+k)^{2}}}
\end{aligned}
$$

For an ideal gas both $D_{\mathrm{m}}$ and $v$ vary inversely with pressure or

$$
D_{\mathrm{m}, \mathrm{o}} P_{\mathrm{o}}=D_{\mathrm{m}, \mathrm{i}} P_{\mathrm{l}}=D_{\mathrm{m}, \mathrm{l}} P_{1}
$$

$D_{\mathrm{m}, 1}$ being the diffusion coefficient in the carrier gas at atmospheric pressure $P_{1}$. For large values of $P$ eqn. 7 together with eqns. 3 and 9 yields:

$$
\bar{v}_{\text {opt,vac }}=\frac{6 D_{\mathrm{m}, 1} P_{1}}{P_{\mathrm{i}, \mathrm{opt}, \mathrm{vac}} r} \sqrt{\frac{3(1+k)^{2}}{11 k^{2}+6 k+1}}
$$

Also if $P \gg 1$ eqn. 8 can be rewritten as:

$$
H_{\text {min,vac }}=\frac{9}{8} r \sqrt{\frac{11 k^{2}+6 k+1}{3(1+k)^{2}}}
$$

Gas velocity through the column

The average gas velocity, $\bar{v}$, through a capillary column is described by the Poiseuille equation

$$
\bar{v}=\frac{3}{32} \frac{r^{2} P_{\mathrm{o}}}{\eta L} \frac{\left(P^{2}-1\right)^{2}}{P^{3}-1}
$$

where $\eta$ is the dynamic viscosity of the carrier gas. If $P \gg 1$ eqn. 12 reduces to:

$$
\bar{v}_{v a c}=\frac{3}{32} \frac{r^{2} P_{i}}{\eta L}
$$

\section{Optimum inlet pressure}

For a given separation problem the number of required theoretical plates, $N_{\text {req }}$, can be calculated using the well known resolution equation. Under optimum chromatographic conditions, the length of the column, $L$, is given by eqn. 8:

$$
L=N_{\mathrm{req}} H_{\mathrm{min}}=N_{\mathrm{req}} f_{1, \mathrm{opt}} r \sqrt{\frac{11 k^{2}+6 k+1}{3(1+k)^{2}}}
$$

Under sub-atmospheric outlet pressures (eqn. 11):

$$
L=N_{\mathrm{req}} H_{\mathrm{min}, \mathrm{vac}}=N_{\mathrm{req}} \frac{9}{8} r \sqrt{\frac{11 k^{2}+6 k+1}{3(1+k)^{2}}}
$$

Using eqns. 7,12 and 3 , the inlet pressure, $P_{1, o p t}$, can be calculated for a given separation problem assuming optimum chromatographic conditions. Thus, $\bar{v}_{\text {poiseul11 }}=$ $\vec{v}_{\text {opt.Golay-Giddings }}$ yields:

$$
\frac{r^{2} P_{\mathrm{o}}}{\eta L}\left(P^{2}-1\right)=64 \frac{D_{\mathrm{m}, \mathrm{o}}}{r} \sqrt{\frac{3(1+k)^{2}}{11 k^{2}+6 k+1}}
$$


Using eqns. 14 and 9, eqn. 16 yields:

$$
P_{\mathrm{i}, \mathrm{opt}}^{2}=\frac{64 P_{1} N_{\mathrm{req}} f_{1, \mathrm{opt}} \eta D_{\mathrm{m}, 1}}{r^{2}}+P_{\mathrm{o}}^{2}
$$

Under vacuum out!et pressure $\left(P_{\mathrm{o}}=0, P \gg 1, f_{1}=9 / 8\right)$ this reduces to:

$$
P_{\mathrm{i}, \mathrm{opt} \text {, vac }}^{2}=72 P_{1} N_{\mathrm{req}} \eta D_{\mathrm{m}, \mathrm{1}} / r^{2}
$$

Basic equations for vacuum outlet pressures $\left(C_{\mathrm{m}} \gg C_{\mathrm{s}}\right)$

$$
P_{\mathrm{i}, \mathrm{opt}, \mathrm{vac}}=\sqrt{72 P_{1}} \sqrt{N_{\mathrm{req}}} \sqrt{\eta D_{\mathrm{m}, \mathrm{i}} / r}
$$

Knowing $P_{i, o p t, v a c}$, eqn. 10 can be rewritten as:

$$
\bar{v}_{\mathrm{opt.vac}}=\sqrt{\frac{\bar{P}_{1}}{2}} \sqrt{\frac{1}{N_{\text {req }}}} \sqrt{\frac{3(1+k)^{2}}{11 k^{2}+6 k+1}} \sqrt{\frac{\bar{D}_{\mathrm{m}, \mathrm{1}}}{\eta}}
$$

From eqns. 15 and 20 the retention time, $t_{R}$, for a given separation problem can be calculated under optimum conditions $\left(P_{1}=P_{\mathrm{i}, \text { opt,vac }}\right)$

$$
t_{R}=t_{\mathrm{o}}(1+k)=\left(L / \bar{v}_{\mathrm{opt}}\right)(1+k)
$$

and $t_{\mathrm{o}}$ is given by:

$$
t_{\mathrm{o}}=\frac{9}{8} \sqrt{\frac{2}{P_{1}}} N_{\mathrm{req}}^{3 / 2} r \frac{11 k^{2}+6 k+1}{3(1+k)^{2}} \sqrt{\frac{\eta}{D_{\mathrm{m}, 1}}}
$$

Comparison of atmospheric and vacuum outlet conditions

For a given wall-coated capillary column operated at otherwise comparable conditions, the following relations can be deduced if $C_{\mathrm{s}}$ is negligible compared to $C_{\mathrm{m}}$. Minimum plate height (eqns. 11 and 8 ).

$$
\frac{H_{\text {min.vac }}}{H_{\text {min.atm }}}=\frac{f_{1 . \text { opt.vac }}}{f_{\text {l.opt,atm }}}
$$

$f_{1.0 p t . v a c}=9 / 8$ and $f_{1, \text { opt.atm }}$ has a value between $1\left(P_{\mathrm{i}}=P_{\mathrm{o}}\right)$ and $9 / 8\left(P_{\mathrm{i}} \gg P_{\mathrm{o}}\right)$. Hence the loss in efficiency is $12.5 \%$ at most. From eqns. 23 and 14 the following expression is obtained

$$
\frac{H_{\text {min,vac }}}{H_{\text {min, atm }}}=\frac{f_{1, \text { opt,vac }}}{f_{1, \text { opt,atm }}}=\frac{N_{\text {opt,atm }}}{N_{\text {opt,vac }}}
$$

or:

$$
\left(N f_{1}\right)_{\mathrm{opt}, \mathrm{vac}}=\left(N f_{1}\right)_{\mathrm{opt}, \mathrm{atm}}
$$

Relation between optimum inlet pressures under atmospheric and vacuum outlet conditions. Substituting eqn. 25 in eqns. 17 and 18 it readily follows:

$$
P_{\text {i,opt,atm }}^{2}=P_{1, \text { opt.vac }}^{2}+P_{1}^{2}
$$


Gain (G) in optimum carrier gas velocity by vacuum operation (eqn. 7).

$$
G=\frac{\bar{v}_{\mathrm{opt}, \mathrm{vac}}}{\bar{v}_{\mathrm{opt}, \mathrm{atm}}}=\frac{D_{\mathrm{m}, \mathrm{o}, \mathrm{vac}} f_{2, \mathrm{op} i, \mathrm{vac}}}{D_{\mathrm{m}, \mathrm{o}, \mathrm{atm}} f_{2, \mathrm{opt}, \mathrm{atm}}}
$$

Substituting the expression for $f_{2}$ (eqn. 3) and using eqn. 9, the gain in speed of analysis is:

$$
G=\frac{P_{\mathrm{i}, \mathrm{opt}, \mathrm{atm}}^{\mathrm{3}}-P_{1}^{3}}{P_{\mathrm{i}, \mathrm{opt} \text { vac }}\left(P_{\mathrm{i}, \mathrm{opt} \text { atm }}^{2}-P_{1}^{2}\right)}
$$

Together with eqn. 26 this yields:

$$
G=\frac{P_{\mathrm{i}, \mathrm{opt}, \mathrm{atm}}^{3}-P_{1}^{3}}{\left(P_{\mathrm{l} \text { opt, atm }}^{2}-P_{1}^{2}\right)^{3 / 2}}=\frac{\left(P_{\mathrm{i}, \mathrm{opt}, \mathrm{vac}}^{2}+P_{1}^{2}\right)^{3 / 2}-P_{1}^{3}}{P_{\mathrm{i}, \mathrm{opt}, \mathrm{vac}}^{3}}
$$

In Fig. I a plot of $G$ versus $P_{\mathrm{i}, \text { opt vac }}$ is shown, stressing the importance of low optimum inler pressures. The consequences of this will be discussed.

Consequences for the pumping capacity of the mass spectrometer. The carrier gas flow, $Q$ (reduced to atmospheric pressure), is given by

$$
Q=\pi r^{2} \bar{v}\left(\bar{P} / P_{1}\right)
$$

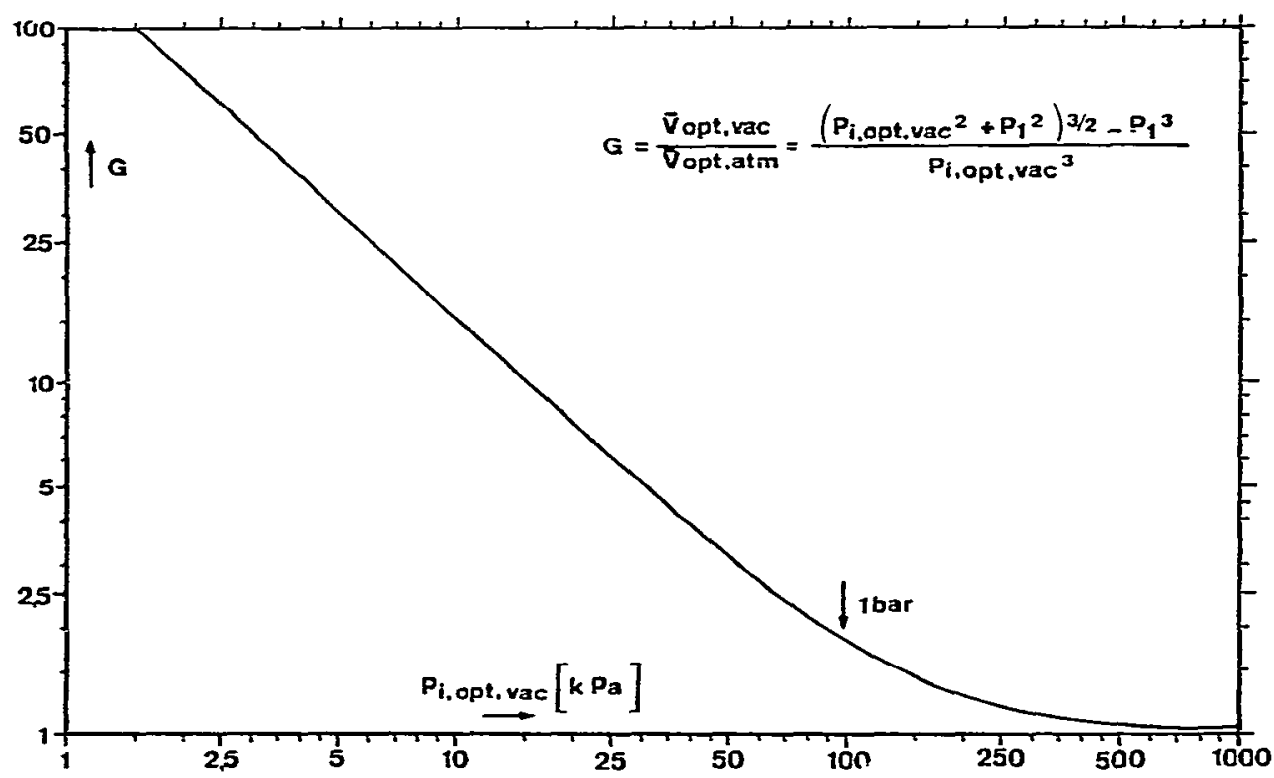

Fig. 1. Gain in speed of analysis $(G)$ by vacuum outlet operation as a function of the optimum inlet pressure $\left(P_{1, \text { opt, vac }}\right)$. 
where $\bar{P}$ is the average column pressure. Therefore, using eqn. 27:

$$
\frac{Q_{\text {opt,vac }}}{Q_{\text {opt.atm }}}=\frac{\bar{v}_{\text {opt,vac }}}{\bar{v}_{\text {opt.atm }}} \cdot \frac{\bar{P}_{\text {opt,vac }}}{\bar{P}_{\text {opt,atm }}}=G \cdot \frac{\bar{P}_{\text {opt,vac }}}{\bar{P}_{\text {opt,atm }}}
$$

Because (cf., eqn. 3):

$$
\begin{aligned}
& \bar{P}=P_{\mathrm{o}} / f_{2} \\
& \bar{P}_{\text {opt,vac }}=2 / 3 P_{\mathrm{i}, \text { opt, vac }} \\
& \bar{P}_{\text {opt.atm }}=\frac{2}{3} \frac{P_{1 \text { opt,atm }}^{3}-P_{1}^{3}}{P_{i, \text { opt,atm }}^{2}-P_{1}^{2}}
\end{aligned}
$$

Thus (cf., eqn. 28):

$$
\frac{\bar{P}_{\text {opt.vac }}}{\bar{P}_{\text {opt.atm }}}=\frac{1}{G}
$$

Consequently:

$$
Q_{\text {opt, vac }}=Q_{\text {opt.atm }}
$$

Notwithstanding the shorter analysis time under vacuum operation, the pump capacity of the mass spectrometer can remain the same.

\section{Discussion}

A given separation problem requires $N_{\text {req }}$ theoretical plates at a certain fixed value of $k$. If furthermore $P \gg 1, C_{\mathrm{m}} \gg C_{\mathrm{s}}$ and the column is operated under optimum conditions (at optimum inlet pressure, $P_{1,0 p t, v a c}$ ), then the following conclusions can be drawn (pressures expressed in bar).

(1) The minimum plate height, $H_{\min }$ (eqns. 8,11 and 23), is independent of the carrier gas and, except for a factor of $9 / 8$, independent of the outlet pressure of the column. The minimum plate height is proportional to $r$, and a function of $k$. The same conclusions are valid for the required column length $L=N H$ (eqns. 14 and 15).

(2) The optimum inlet pressure, $\boldsymbol{P}_{\text {i.opt,vac }}$ (eqn. 19), is proportional to $1 / r$, $\sqrt{N_{\text {req }}}$ and $\sqrt{\eta D_{\mathrm{m} .1}}$. From Table $I$ it can be seen that $P_{i, o p t . v a c}$ has a low value for isobutane, but higher values for the carrier gases helium and hydrogen. For a given column a simple relation holds between the optimum inlet pressures under vacuum and atmospheric outlet pressures (eqn. 26):

$$
P_{\mathrm{i}, \mathrm{opt}, \mathrm{vac}}^{2}=P_{\mathrm{i} \text { opt,atm }}^{2}-1
$$

(3) The optimum average carrier gas velocity under vacuum outlet pressures, $\bar{v}_{\text {opt.vac }}$ (eqn. 20), is independent of $r$, but proportional to $1 / \sqrt{N_{\text {req }}}$ and $\sqrt{D_{\mathrm{mr} .1} / \eta}$. The smallest analysis time is obtained with hydrogen as the carrier gas (Table I).

(4) Comparing $P_{\mathrm{o}}=0$ and $P_{\mathrm{o}}=1$ bar for a given column at constant experi- 
TABLE I

INFLUENCE OF DIFFERENT CARRIER GASES ON OPTIMUM PARAMETERS CALCULATED FOR $n-C_{12} \mathrm{H}_{26}$ AT $400^{\circ} \mathrm{K}$ AND 1 BAR

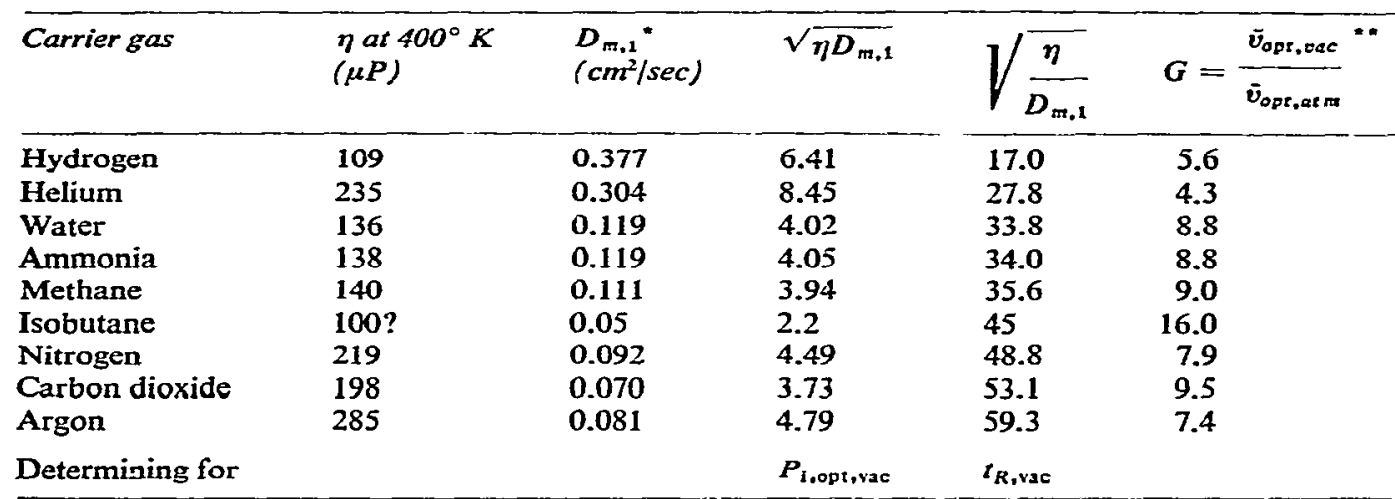

- Calculated according to ref. 15.

* At $N=10^{4}$ and $r=0.2 \mathrm{~mm}$.

mental conditions, it appears that vacuum operation always leads to a higher optimum carrier gas velocity. The ratio of optimum gas velocities is given by eqn. 29:

$$
G=\frac{\left(P_{\text {s,opt,vac }}^{2}+1\right)^{3 / 2}-1}{P_{i, \text { opt.vac }}^{3}}
$$

This ratio, indicating the gain in the speed of analysis, increases strongly for lower inlet pressures $\left(P_{i, \text { opt,vac }}<1\right.$ bar $)$, approaching $3 /\left(2 P_{i, \text { opt,vac }}\right)$. Lower inlet pressures means in practical terms the use of wide bore and/or shorter columns. In Table $I$, values of $G$ for different carrier gases are given for a $0.4 \mathrm{~mm}$ I.D. column having 10,000 theoretical plates. Using the chemical ionization reagent gases methane, isobutane or ammonia as carrier gases, the gain in speed of analysis is even higher than obtained with nitrogen. If more theoretical plates are required, the consequence is an increase in $P_{\text {i,opt,vac, }}$ and a decrease in $G$ (Fig. 1).

(5) Vacuum outlet operation results in narrower and thus higher peaks for a given amount of sample and therefore improves detection limits.

\section{RESULTS AND CONCLUSIONS}

Experimental results indicate the validity of the theory. The obtained data are summarized in Table II and Fig. 2.

As predicted by theory, under vacuum conditions no significant difference in plate number is found between the carrier gases nitrogen and helium. Comparing the experimental results for the $30 \mathrm{~m}$ column, operated with nitrogen at $P_{\mathrm{o}}=0$ and $P_{\mathrm{o}}=1 \mathrm{bar}$, respectively, no evidence is found for a loss in plate number by a factor $f_{1}=9 / 8$. The difference between $N_{\text {calc. }}$ and $N_{\text {meas. }}$ under atmospheric outlet pressures is probably duc to the contribution of the $C_{\mathrm{s}}$ term from the Golay-Giddings equation.

Calculated and experimental values of $P_{\mathrm{i}, \mathrm{opt}}, \bar{v}_{\mathrm{opr}}$ and $N$ agree very well. The 
TABLE $\mathbf{I}$

COMPARISON OF DATA FOR A SE-30 GLASS CAPILLARY COLUMN, OPERATED AT OPTIMUM SEPARATION CONDITIONS AT VACUUM AND ATMOSPHERIC OUTLET PRESSURES, RESPECTIVELY

Column diameter, $0.4 \mathrm{~mm}$ I.D.; film thickness, $0.4 \mu \mathrm{m}$. All data for $n-\mathrm{C}_{12} \mathrm{H}_{26}$ at $400^{\circ} \mathrm{K}$ (capacity ratio $k=2$ ).

\begin{tabular}{|c|c|c|c|c|c|c|c|}
\hline & & \multicolumn{3}{|c|}{$P_{\circ}=0, L=60 \mathrm{~m}$} & \multirow{2}{*}{\multicolumn{2}{|c|}{$\frac{P_{0}=0, L=30 \mathrm{~m}}{\text { Nitrogen }}$}} & \multirow{2}{*}{$\begin{array}{l}P_{0}=1 \text { bar, } L=30 \mathrm{~m} \\
\text { Nitrogen }\end{array}$} \\
\hline & & Hydrogen & Helium & Nitrogen & & & \\
\hline$P_{1, \text { opt }}($ bars) & $\begin{array}{l}\text { calc. } \\
\text { mcas. }\end{array}$ & $\begin{array}{r}1.22 \\
-\end{array}$ & $\begin{array}{l}1.60 \\
1.55\end{array}$ & $\begin{array}{l}0.85 \\
0.80\end{array}$ & $\begin{array}{l}0.60 \\
0.60\end{array}$ & & $\begin{array}{l}1.16 \\
1.25\end{array}$ \\
\hline $\bar{v}_{\mathrm{opt}}(\mathrm{cm} / \mathrm{sec})$ & $\begin{array}{l}\text { calc. } \\
\text { meas. }\end{array}$ & ${ }^{66}-$ & $\begin{array}{l}40 \\
36\end{array}$ & $\begin{array}{l}23 \\
21\end{array}$ & $\begin{array}{l}32 \\
29\end{array}$ & & $\begin{array}{l}11.7 \\
11.6\end{array}$ \\
\hline$t_{R}(\mathrm{sec})$ & $\begin{array}{l}\text { calc. } \\
\text { meas. }\end{array}$ & ${ }^{279}-$ & $\begin{array}{l}456 \\
495\end{array}$ & $\begin{array}{l}798 \\
879\end{array}$ & $\begin{array}{l}282 \\
327\end{array}$ & & $\begin{array}{l}783 \\
933\end{array}$ \\
\hline$N\left(\times 10^{3}\right)$ & $\begin{array}{l}\text { calc. } \\
\text { meas. }\end{array}$ & ${ }^{190}$ & $\begin{array}{l}190 \\
177\end{array}$ & $\begin{array}{l}190 \\
180\end{array}$ & $\begin{array}{l}95 \\
96\end{array}$ & & $\begin{array}{r}107 \\
98\end{array}$ \\
\hline \multirow[t]{2}{*}{$G=\frac{\bar{v}_{\mathrm{opt} . v a c}}{\bar{v}_{\mathrm{opt.stra}}}$} & calc. & 1.6 & 1.4 & 2.1 & & 2.7 & \\
\hline & meas. & - & - & - & & 2.5 & \\
\hline
\end{tabular}

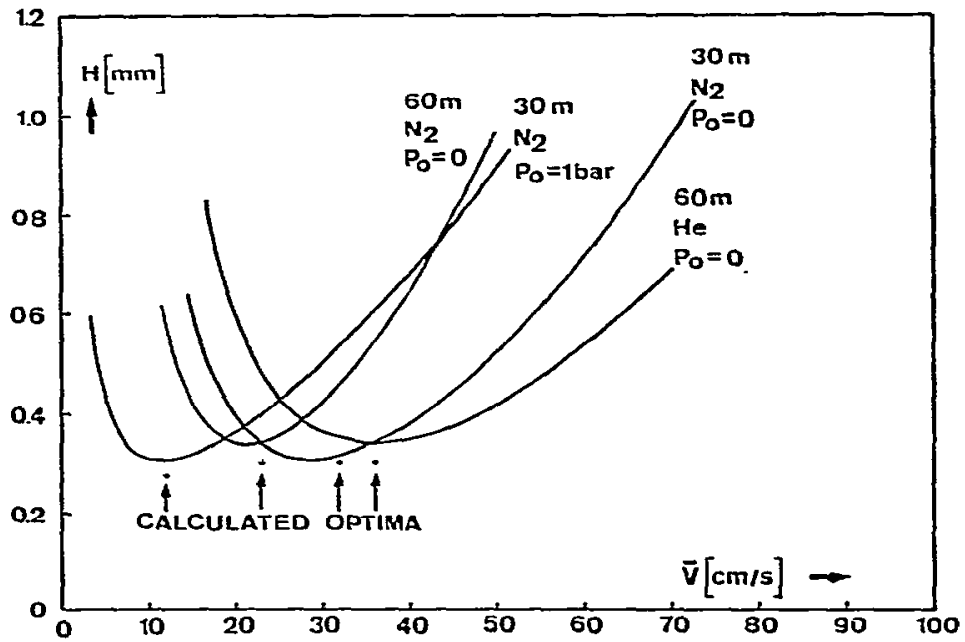

Fig. 2. Measured $H$ vs. $\bar{v}$ curves (computer fitted) for a SE-30 glass capillary column ( $0.4 \mathrm{~mm}$ I.D.). Column length, $L$, carrier gas and column outlet pressure as indicated. Data were obtained with $n-\mathrm{C}_{12} \mathrm{H}_{26}$ at $400^{\circ} \mathrm{K}(k=2)$.

results obtained with the $30 \mathrm{~m}$ column at $P_{0}=0$ demonstrate a gain in analysis time of a factor 2.5 , as predicted by theory. The derived equations show that much larger "gain" factors can be obtained for chemical ionization reagent gases such as isobutane (cf., Table I). The optimum volume flow (reduced to 1 bar) to the mass spectrometer is unaffected. From the constancy of $N$ and the increase of the optimum linear carrier gas velocity, it appears that the peak width is decreased under vacuum outlet pres- 
sures. The effect is an improvement in detection limits for both concentration and mass-flow detectors.

The advantageous effects described above hold for WCOT columns where the resistance towards mass transfer in the liquid phase is negligible compared to that in the gas phase. This is valid for capillaries with uniformly distributed thin liquid films, but also for wide-bore columns with thick films. The latter have higher sample capacities, show less adsorption and facilitate injection.

\section{REFERENCES}

1 J. G. Leferink and P. A. Leclercq, J. Chromatogr., 91 (1974) 385.

2 D. Henneberg, U. Henrichs and G. Schomburg, Chromatographia, 8 (1975) 449.

3 F. Vangaever, P. Sandra and M. Verzele, Chromatographia, 12 (1979) 153.

4 F. W. Hatch and M. E. Parrish, Anal. Chem., 50 (1978) 1164.

5 J. C. Giddings, Anal. Chem., 34 (1962) 314.

6 N. Sellier and G. Guiochon, J. Chromatogr. Sci., 8 (1970) 147.

7 P. F. Varadi and F. Ettre, Anal. Chem., 35 (1963) 410.

8 G. A. F. M. Rutten and J. A. Luyten, J. Chromatogr., 74 (1972) 177.

9 G. A. F. M. Rutten and J. A. Rijks, J. High Resolut. Chromatogr. Chromatogr. Commun., 1 (1978) 279.

10 G. Schomburg, R. Dielmann, H. Borwitzky and H. Husmann, J. Chromatogr., 167 (1978) 337.

11 M. Golay, in D. H. Desty (Editor), Gas Chromatography 1958, Butterworths, London, 1959, p. 36.

12 J. C. Giddings, S. L. Seager, L. R. Stucki and G. H. Stewart, Anal. Chem., 32 (1960) 867.

13 J. C. Giddings, Anal. Chem., 36 (1964) 741.

14 C. A. Cramers, F. A. Wijnheymer and J. A. Rijks, J. High. Resolut. Chromatogr. Chromatogr. Commun., 2 (1979) 329.

15 E. N. Fuller, P. D. Schettler and J. C. Giddings, Ind. Eng. Chem., 58 (1966) 19.

16 M. Novotny, Chromatographia, 2 (1969) 350. 